\title{
FEM SIMULATIONS FOR THE OPTIMIZATION OF THE INLET GATE SYSTEM IN RAPID INVESTMENT CASTING PROCESS FOR THE REALIZATION OF HEAT EXCHANGERS
}

\author{
D. Almonti $₫$, G. Baiocco, and N. Ucciardello \\ Department of Enterprise Engineering Mario Lucertini, University of Rome “Tor Vergata," Via del Politecnico 1, 00133 \\ Rome, Italy \\ E. Mingione \\ Department of Engineering, University of Campania “Luigi Vanvitelli,” Via Roma, 9, 81031 Aversa, Italy
}

Copyright $(\subset) 2021$ The Author(s)

https://doi.org/10.1007/s40962-021-00668-7

\begin{abstract}
Over the last decades, additive manufacturing (AM) has become the principal production technology for prototypes and components with high added value. In the production of metallic parts, AM allows producing complex geometry with a single process. Also, AM admits a joining of elements that could not be realized with traditional methods. In addition, AM allows the manufacturing of components that could not be realized using other types of processes like reticular structures in heat exchangers. A solid mold investment casting that uses printed patterns overcomes typical limitations of additive processes such as expensive machinery and challenging process parameter settings.

aims at defining and investigating the principal foundry parameters to achieve a defect-free heat exchanger. For this purpose, different device CAD models were designed, considering four pipes' thickness and length. Finite element method numerical simulations were performed to optimize the design of the casting process. Three different gate configurations were investigated for each length. The numerical investigations led to the definition of a castability range depending on flat heat pipes geometry and casting parameters. The optimal gate configuration was applied in the realization of AM patterns and casting processes
\end{abstract} Indeed, rapid investment casting provides for a foundry epoxy pattern reproducing the component to exploit in the lost wax casting process. In this paper, aluminium radiators with flat heat pipes seamlessly connected with a cellular structure were conceived and produced. This paper
Keywords: rapid investment casting, lost wax casting, heat exchangers, FEM

metallic materials such as stainless steel, ${ }^{5,6,19,25,47,58}$ titanium alloys, ${ }^{41,54}$ aluminium, ${ }^{29,44}$ and nickel-based alloys. ${ }^{18}$ Within 10 years (2003-2013), the direct part production passed from 3.9 to $34.7 \%$ of the AM total product and service revenue. ${ }^{10}$ Directed energy deposition (DED) and powder bed fusion (PBF) are the principal processes exploited to fabricate metallic parts with AM. The former provides for in situ delivery of metal through powder or wires in addition to a focused energy source. In the latter, a powder bed is selectively melted to produce a $3 \mathrm{D}$ layer by layer structure. Usually, an electron or laser beam is exploited as the thermal source. However, selective laser melting (SLM) for PBF allows high design freedom and

Received: 12 April 2021 / Accepted: 26 July 2021 /

Published online: 21 August 2021 
production of 3D objects with demanding geometries. $^{34,40,49,50}$

Wire and arc additive manufacturing (WAAM) is a DED$\mathrm{AM}$ process fed by a metallic wire which is relatively simple and low cost compared to other AM methods. ${ }^{12}$ However, it involves severe residual stresses because of the high deposition rate and heat inputs. ${ }^{14}$ Also, the high energy and wide heat-affected zone produced by the WAAM afflict the metal deposition in the micro-scale level, concerning the powder-based methods. ${ }^{20}$ However, besides few studies, ${ }^{39,46,56,57}$ a thorough understanding of the thermal history along with mechanical and surface properties as a function of the process conditions lacks is lacking. 36

The application of AM for heat transfer devices is of great interest allowing miniaturization and performance improvement. The latter may be achieved with the realization of complex designs, capillarity structures, channel arrays, and more. However, many challenges in engineering AM processes must still be faced to achieve workpieces free of defects and high-quality features to match the tight standards required for engineering applications. ${ }^{45}$

Common AM component defects include discontinuities, porosity, highly textured columnar grains, complex phases, and compositional variations. ${ }^{11}$ However, most of the features inherited from the manufacturing process can be reduced by post heat treatment like hot isostatic pressing (HIP). ${ }^{21,28,31}$ Nevertheless, porosity production is still a major problem during AM of aluminium alloys..$^{8,9,33,52}$ In WAAM, the metal suffers a complex thermal process and anisotropies within the microstructure and, therefore, in the components properties. ${ }^{27,58}$

Proper management of the process parameters, e.g., temperature gradient, solidification rate, alloy composition, thermal cycles and high cooling rate, hinder the anisotropies. $^{24,59}$ The SLM process parameters and building strategy also have a broad influence on the structure of the part and, thus, on the mechanical properties. Hence, they must be specifically selected for a given combination of material, geometry and size. In general, a rapid cooling rate produces high residual stresses and fine microstructure. In the powder bed condition, this leads to the creation of porosity. Also, the orientation of the components during the SLM processes exert an influence on grain growth and surface texture. ${ }^{43,48}$ Properties such as density and surface roughness are fundamental as they noticeably affect the heat transfer. Generally, solidified grains present textured large columnar grains tough with equiaxed grains close to the melt pool surface. , $23,30,55,63$

The morphology transition within the solidification phase is governed by the ratio of thermal gradient $G$ on the kinetics of mass transfer $\mathrm{R}$ rule. Several grains configuration can be achieved through the process parameter managements, from equiaxed dendritic to planar. These concerns are valid all the more reason when considering thin-walled components. ${ }^{60}$ The smaller the $3 \mathrm{D}$ structure thickness, the higher is the defects and morphology influence on their properties.

Aluminium flat thin pipes find several applications in different sectors such as automotive, aeronautics, conditioning, and heat exchange applications. Up to now, a typical production process of hollowed flat aluminium pipes is continuous extrusion. However, several limitations like expansive production costs and billet pre-treatment requirements afflict this manufacturing process. Also, the welded pipes produced cannot be exploited for high-pressure liquid containment. ${ }^{61}$ Instead, flow forming (FF) is a forming process exploited to produce seamless thin-wall tubes from thermally treated preformed tubes prepared by extrusion or forging processes. ${ }^{13,35,37}$ A challenging multiple parameters setting is required for the FF process, which being a dynamic process requires demanding management. Thus, the variables are often set based on engineers' experience and practice. However, the flow-formed pipes can respect the higher standards in specific strength, geometrical tolerance and surface roughness. ${ }^{42}$

A lately proposed rapid investment casting (RIC) overtake both the limitation of AM and casting. It provides for the 3D printing of meltable models made by foundry resin exploited for a casting process. It has already been proved how this methodology is valuable for metal foams and reticular structure production with outstanding results. ${ }^{2,4,62}$ It is mainly due to the peculiar conformation of the metallic cellular structures, which offer a wide exchange surface. ${ }^{7}$ Indeed, metal foams have already been applied in heat exchange prototypal devices. ${ }^{3,22,32,38}$ In heat exchange devices, this is important as such the contact between these surfaces and flat heat pipes.

Through RIC, it is possible to integrate metallic reticular structure branches within the tube wall bulk in the fundable model. The devices produced by foundry processes will feature a seamless connection between heat pipes and heat exchange surface that improve the heat dissipation performance. The main concerns regard the thickness of the flat tubes achievable with the foundry processes as even modest defects on the thin-walled structure would compromise the device's functionality.

The finite element method (FEM) help to prevent flaw that may arise during the metal casting. ${ }^{15-17,26,51,53}$ Huang et al. $^{26}$ optimized a casting process through numerical simulations of the gating system for precision 17-4 PH stainless steel rotor used for hemodialysis machines.

Both flow turbulence and inadequate supply and internal shrinkage can be reduced through appropriate numerical 
investigation. Fang et al. ${ }^{17}$ investigated the preliminary design in investment casting of an exhaust manifold using a numerical analysis with FEM investigation. The results of numerical simulations highlighted the eventuality to optimize and redesign the parameters involved during the casting process. Also, the results obtained were checked and confirmed by the actual production and testing of the exhaust manifold.

The study aims at defining the main foundry parameters to achieve an aluminium radiator free of defects, with flat heat pipes seamlessly connected to a cellular structure. CAD models of the device were produced, considering four different pipes thickness and length. Also, a numerical simulation was performed to design the casting process and avoid defects. The CAD patterns were manufactured through 3D printing and cast with the RIC processes. Numerical investigation and experimental work led to the definition of a range of process parameter values for which the process is feasible, which depends on the geometry of the flat heat pipes.

\section{Materials and Methods}

Different radiator models made of AC-44300 aluminium alloy (Table 1) with a different height $(20,40,60,80 \mathrm{~mm})$ were designed and realized. Their geometry was produced through Solidworks. Initially, a 2D sketch with four different pipe thicknesses $(0.5,1,1.5,2 \mathrm{~mm})$ was realized, as shown in Figures 1 and 2.

The different models are shown in Figure 2. An XFAB 2000 DWS stereolithographic 3D printer was exploited for the realization of the patterns with a photosensitive resin (FUSIA 444) (Table 2). The reticular structure allows a printing process without external supports. The patterns printed were polymerized for 1 hour in a UV oven. Figure 3 depicts the foundry patterns used for the casting process.

Table 1. EN 44300 Chemical Composition \%

\begin{tabular}{lcc}
\hline Elements & $\min$ & $\max$ \\
\hline $\mathrm{Si}$ & 10.5 & 13.5 \\
$\mathrm{Fe}$ & 0.45 & 0.90 \\
$\mathrm{Cu}$ & 0.08 & \\
$\mathrm{Mn}$ & 0.55 & \\
$\mathrm{Zn}$ & 0.15 & \\
$\mathrm{Ti}$ & 0.15 & \\
\hline
\end{tabular}

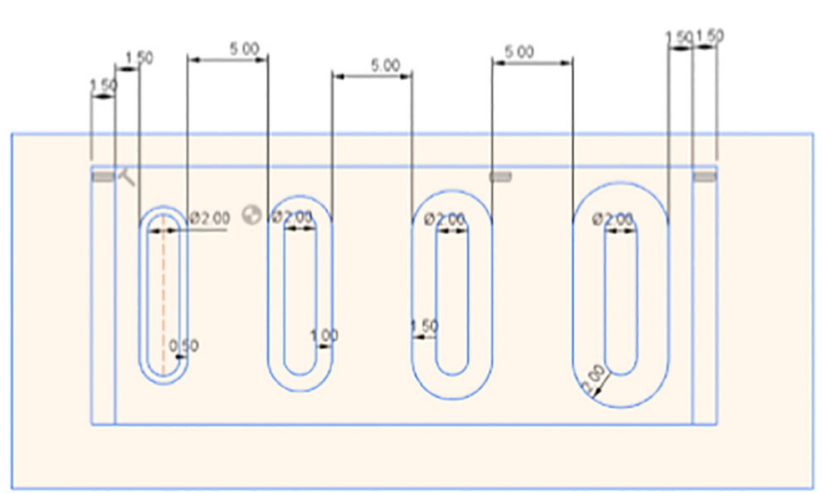

Figure 1. 2D sketch of the obtained radiators with different pipe thicknesses.

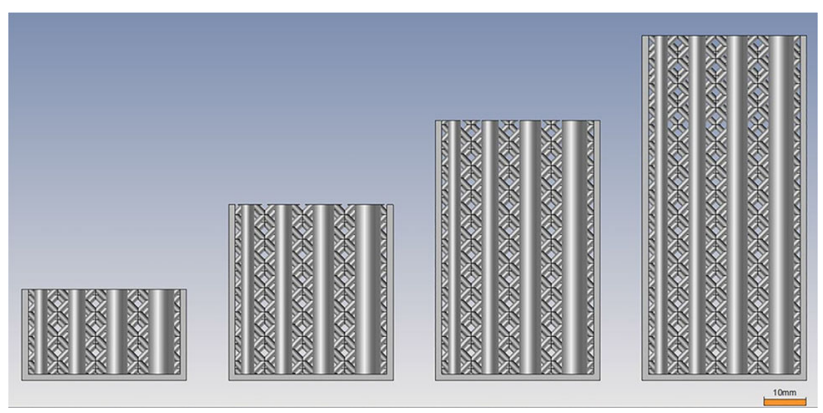

Figure 2. CAD models of the radiators. Different heights of the pipes are, respectively: (a) $20 \mathrm{~mm}$; (b) $40 \mathrm{~mm}$; (c) $60 \mathrm{~mm}$; (d) $80 \mathrm{~mm}$.

Table 2. Characteristics of Photopolymer FUSIA 444

$\begin{array}{lc}\text { Technical characteristics of the liquid material } \\ \text { Environmental values for } & 22-27{ }^{\circ} \mathbf{C} \text {-max RH } \\ \text { Use } & 40-60 \% \\ \text { Appearance/Color } & \text { Liquid/Yellow } \\ \text { Viscosity } & 300-600 \mathrm{MPa} \cdot \mathrm{s} \text { at } 25^{\circ} \mathbf{C} \\ \text { Density } & 1.08 \mathrm{~g} / \mathrm{cm}^{3} \\ \text { Technical characteristics of the resin after UV curing } \\ \text { Surface hardness } & 56-63 \mathrm{Shore} \mathrm{D} \\ \text { Flexural strength } & 10-16 \mathrm{MPa} \\ \text { Flexural modulus } & 240-270 \mathrm{MPa} \\ \text { Elongation at break } & 6-11 \% \\ \text { Tensile strength } & 6-13 \mathrm{MPa}\end{array}$

The plaster mould was produced by mixing plaster powder and water at $25^{\circ} \mathrm{C}$ for 30 minutes. The exploitation of a vibrating platform and a vacuum machine after the stirring avoid air inclusions. The expendable pattern is plunged in the plaster suspension in a foundry cylinder. The application of a thermal cycle consolidates the mould structure and allows the removal of the pattern (Figure 4).

The casting process was analyzed through numerical simulation performed with inspire cast. The investigation aim 


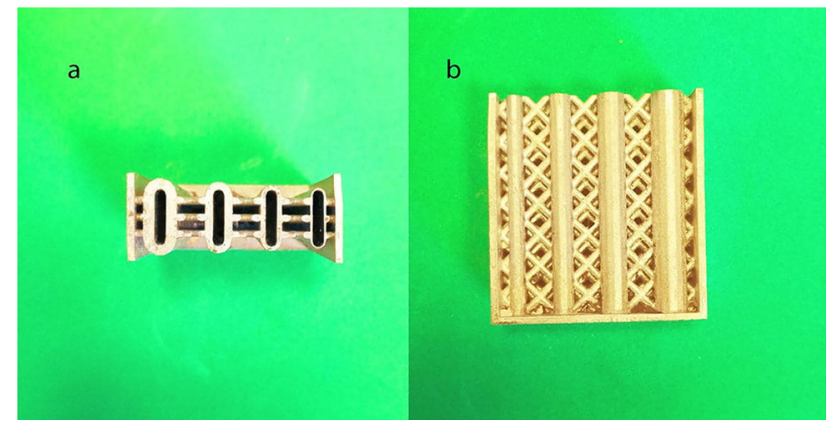

Figure 3. Resin model of the radiators with $60 \mathrm{~mm}$ pipes, (a) upper side view, (b) front-side view.

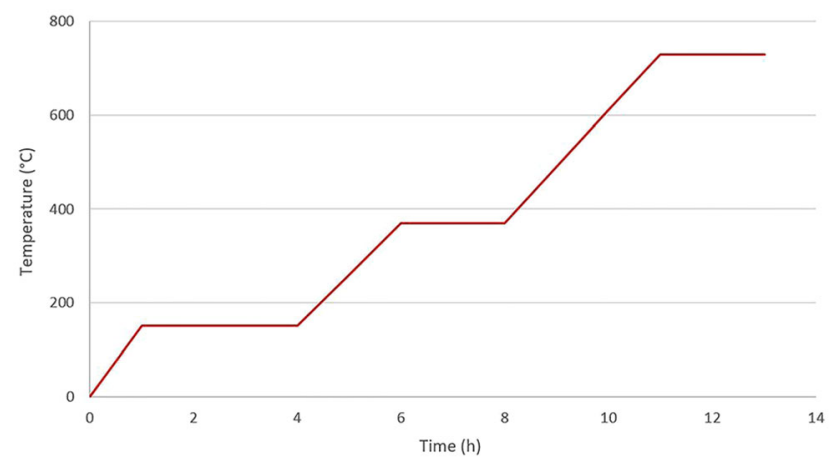

Figure 4. Thermal cycle imposed to the plaster mold.

was to prevent defects such as shrinkage cavities and porosities. These defects depend on several factors like a non-uniform temperature gradient during metal solidification and cooling, the cooling conditions, component geometry and feeding gate placement. The influence of casting location on the tree is not considered because the foundry machine uses a cylinder with a diameter of 120 $\mathrm{mm}$ that not allows the assembly of multiple patterns with these sizes.

The casting process is governed by a few relationships: mass conservation, Navier-Stokes equation, energy conservation, volume-of-fluid function (VOF) and $k-\epsilon$ equations. The former is crucial to calculate the mass conservation during the metal flow in the feeding phase and expressed as follow:

Table 3. Mesh Characteristics of Each Model

\begin{tabular}{lll}
\hline Model & Number of nodes & Number of elements \\
\hline $20 \mathrm{~mm}$ pipes & 191650 & 798042 \\
$40 \mathrm{~mm}$ pipes & 340246 & 1411500 \\
$60 \mathrm{~mm}$ pipes & 482963 & 1995573 \\
$80 \mathrm{~mm}$ pipes & 634799 & 2633214 \\
\hline
\end{tabular}

Table 4. Boundary Conditions Used During Simulations

\begin{tabular}{ll}
\hline Boundary conditions & Value \\
\hline Molten metal temperature $\left[{ }^{\circ} \mathbf{C}\right]$ & 730 \\
Plaster mold preheated temperature $\left[{ }^{\circ} \mathbf{C}\right]$ & 580 \\
Casting time $[\mathrm{s}]$ & 0.5 \\
\hline
\end{tabular}

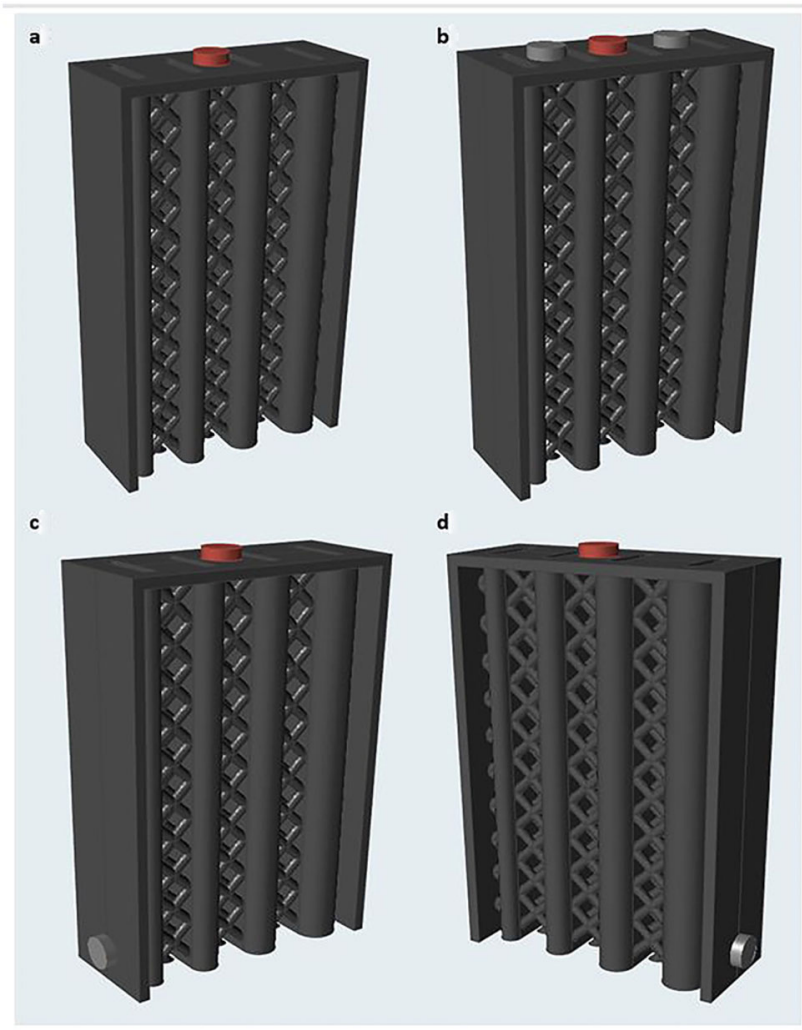

Figure 5. Gate positioning on the $60 \mathrm{~mm}$ pipes height model: (a) One inlet gate; (b) Three inlet gates; (c) Two inlet gates (lateral gate is near lowest thickness pipe); (d) Two inlet gates (lateral gate is near highest thickness pipe).

$$
\frac{\partial \rho}{\partial t}+\nabla \cdot(\rho \bar{u})=0
$$

where $\rho$ is the fluid density, $t$ is the time and $\bar{u}$ the velocity vector. The Navier-Stokes equation allows evaluating pressure and velocity fields:

$\rho \frac{\partial \bar{u}}{\partial t}+\rho \bar{u} \cdot \nabla \bar{u}=-\nabla P+\mu \nabla^{2} \bar{u}+\rho \bar{g}$

Eqn. 2

with $P$ as the pressure, $\bar{g}$ gravitational acceleration and $\mu$ dynamic viscosity of the molten metal. The energy conservation equation allows the temperature field 
Table 5. Simulation Time for the Various Gate Configurations and Pipe Length Analyzed

\begin{tabular}{lllll}
\hline & \multicolumn{4}{l}{ Simulation time [min] } \\
\cline { 2 - 5 } $\begin{array}{l}\text { Pipe length } \\
\text { Gate configuration }\end{array}$ & $20 \mathrm{~mm}$ & $40 \mathrm{~mm}$ & $60 \mathrm{~mm}$ & $80 \mathrm{~mm}$ \\
\hline 1 Upper Inlet & 60 & 100 & 157 & 238 \\
3 Upper Inlet & 56 & 140 & 198 & 228 \\
1 Upper 1 Lateral Inlet LH & 42 & 92 & 150 & 212 \\
1 Upper 1 Lateral Inlet RH & 46 & 88 & 136 & 194 \\
\hline
\end{tabular}

calculation and, consequentially, the solidification process management, with the following formula:

$\rho \frac{\partial H}{\partial t}+\rho H \nabla \cdot \bar{u}-\nabla \cdot(k \nabla T)-q=0$,

Eqn. 3

where $H$ is the enthalpy and $q$ the volumetric heat flux. For the determination of the molten metal patterns, the volume function equation was used and combined with NavierStokes, written in the form:

$\frac{\partial F}{\partial t}+\bar{u} \cdot \nabla F_{v}=0$ where $F_{v}$ is the volume-of-fluid function, which is set to 0 when the calculation cell is empty, otherwise to 1 . A $k-\varepsilon$ turbulence model was used to define the turbulence parameters :

$$
\begin{aligned}
& \frac{\partial k_{e}}{\partial t}+u_{j} \frac{\partial k_{e}}{\partial x_{j}}=\frac{\partial}{\partial x_{j}}\left[\left(u+\frac{u_{t}}{\sigma_{k}} \frac{\partial k_{e}}{\partial x_{j}}\right)\right]+P_{k e}-\varepsilon \quad \text { Eqn. 5 } \\
& \frac{\partial \varepsilon}{\partial t}+u_{j} \frac{\partial \varepsilon}{\partial x_{j}}=\frac{\partial}{\partial x_{j}}\left[\left(u+\frac{u_{t}}{\sigma_{\varepsilon}} \frac{\partial \varepsilon}{\partial x_{j}}\right)\right]+C_{\varepsilon 1} P_{k e} \frac{\varepsilon}{k_{e}}-C_{\varepsilon 2} \frac{\varepsilon^{2}}{k_{e}},
\end{aligned}
$$

Eqn. 6

where $u_{j}$ represents velocity components in the corresponding direction, $\varepsilon$ is the dissipation rate of turbulence kinetic energy, $k_{e}$ is the turbulence kinetic energy, $\sigma_{k}$ is the Prandtl number corresponding to turbulence kinetic energy and $\sigma_{\varepsilon}$ the Prandtl number corresponding to the dissipation rate. The term $u_{t}$ is the turbulence eddy viscosity, defined as follows:

$u_{t}=\frac{\rho C_{\mu} k_{e}^{2}}{\varepsilon}$

Eqn. 7

The values of the constants used in the turbulence model were $C_{\mu}=0.09, \quad \sigma_{k}=1.00, \quad \sigma_{\varepsilon}=1.30, \quad C_{\varepsilon 1}=1.44$, $C_{\varepsilon 2}=1.92$. Equations $1-7$ describe the physical model of

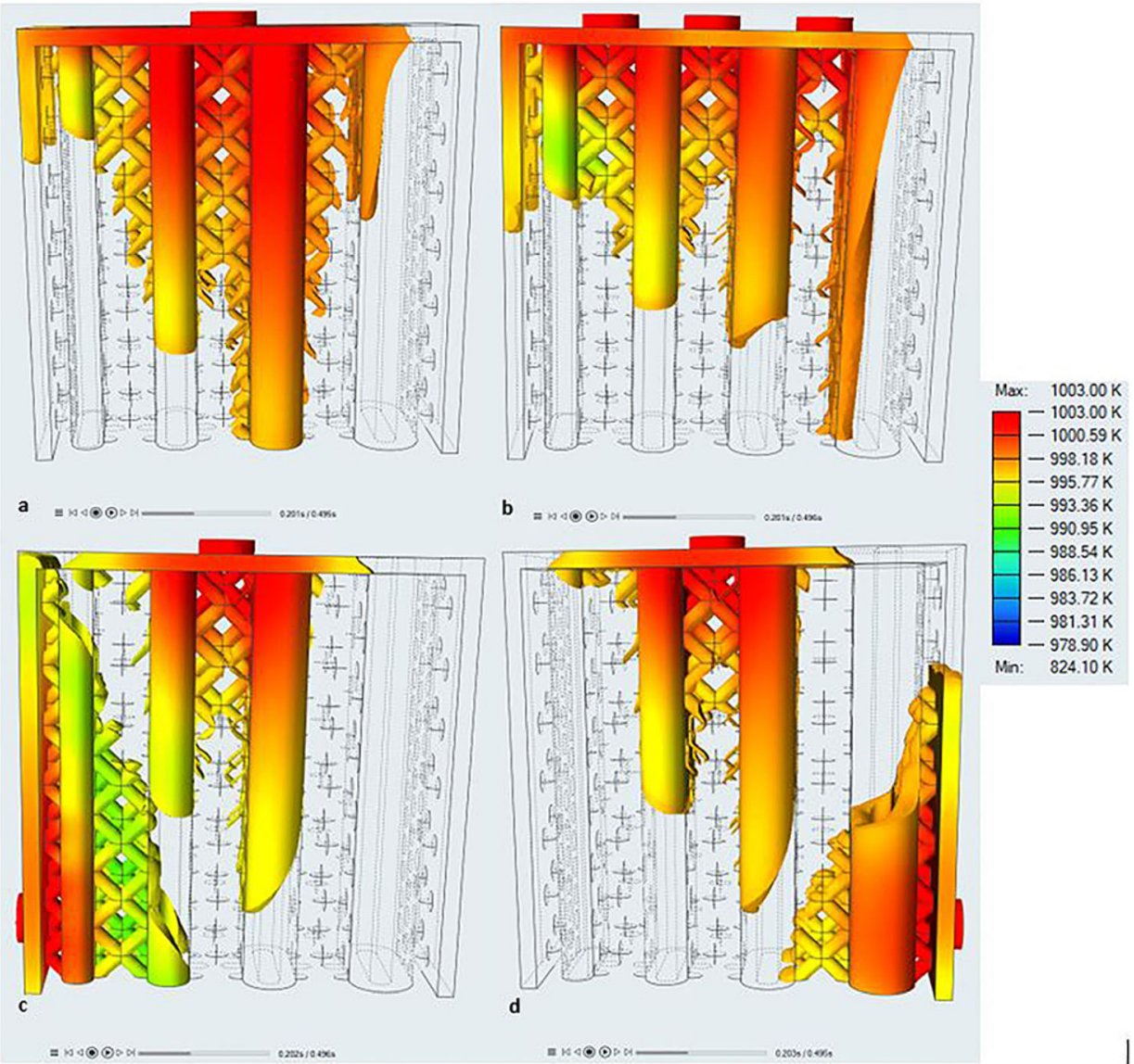

Figure 6. Filling of the $40 \mathrm{~mm}$ pipes model at $t=0,2 \mathrm{~s}$ for each gate configuration: (a) One inlet gate; (b) Three inlet gates; (c) Two inlet gates (lateral gate is near lowest thickness pipe); (d) Two inlet gates (lateral gate is near highest thickness pipe). 


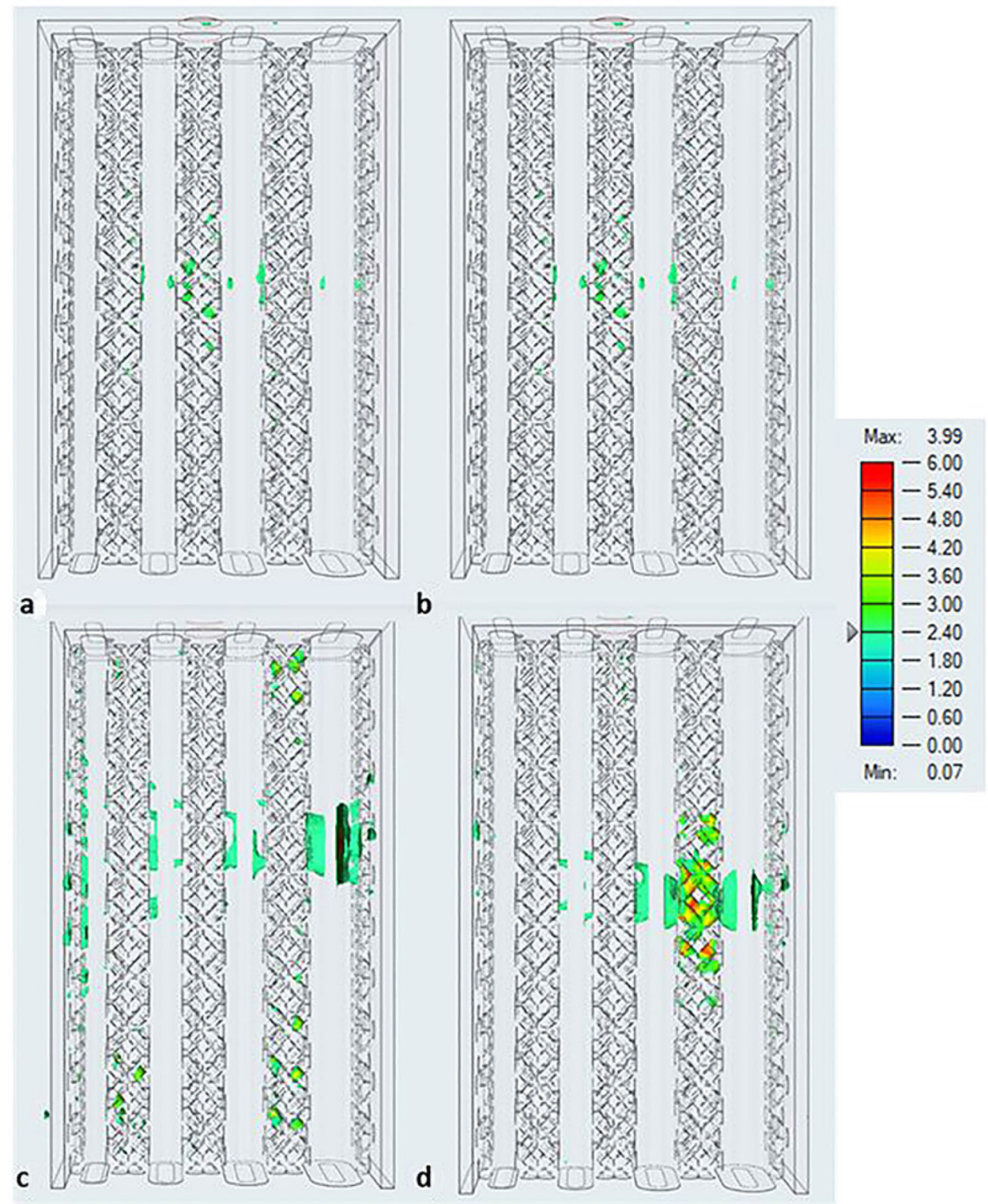

Figure 7. Micro-porosity analysis for the $60 \mathrm{~mm}$ pipes model at the end of solidification for each gate configurations: (a) One inlet gate; (b) Three inlet gates; (c) Two inlet gates (lateral gate is near lowest thickness pipe); (d) Two inlet gates (lateral gate is near highest thickness pipe).

the molten metal dynamic solidification. Inspire cast solves these equations through a domain discretization (meshing) and a finite element method (FEM) approach. This kind of approach, differently from finite difference method (FDM) one, has a higher accuracy. However, this means higher simulation time, since it is harder to reach convergence each step.

The porosities in the aluminium alloys can derive from contraction phenomena or gas entrapment. The model used for the porosities and shrinkage prediction follows the Niyama criterion, which is used only for the porosities caused by the contraction of the metal during the solidification. The threshold value of the criterion is determined experimentally for each alloy, and the value $N_{y}$ is calculated with the following equation:

$N_{\mathrm{y}}=\frac{G}{\sqrt{R}}<C_{\text {Niyama }}$,

Eqn. 8

where $G$ denotes the local temperature gradient of interest $(\mathrm{K} / \mathrm{m}) ; R$ is the cooling rate; and $C_{\text {Niyama }}$ is the threshold value of the Niyama criterion. A tetrahedral mesh was used for the simulations. Table 3 shows the number of nodes and elements generated for simulation processes. Boundary conditions for each simulation are defined in Table 4

The working volume of the foundry machine used and the dimensions of the components represent a limit that is 


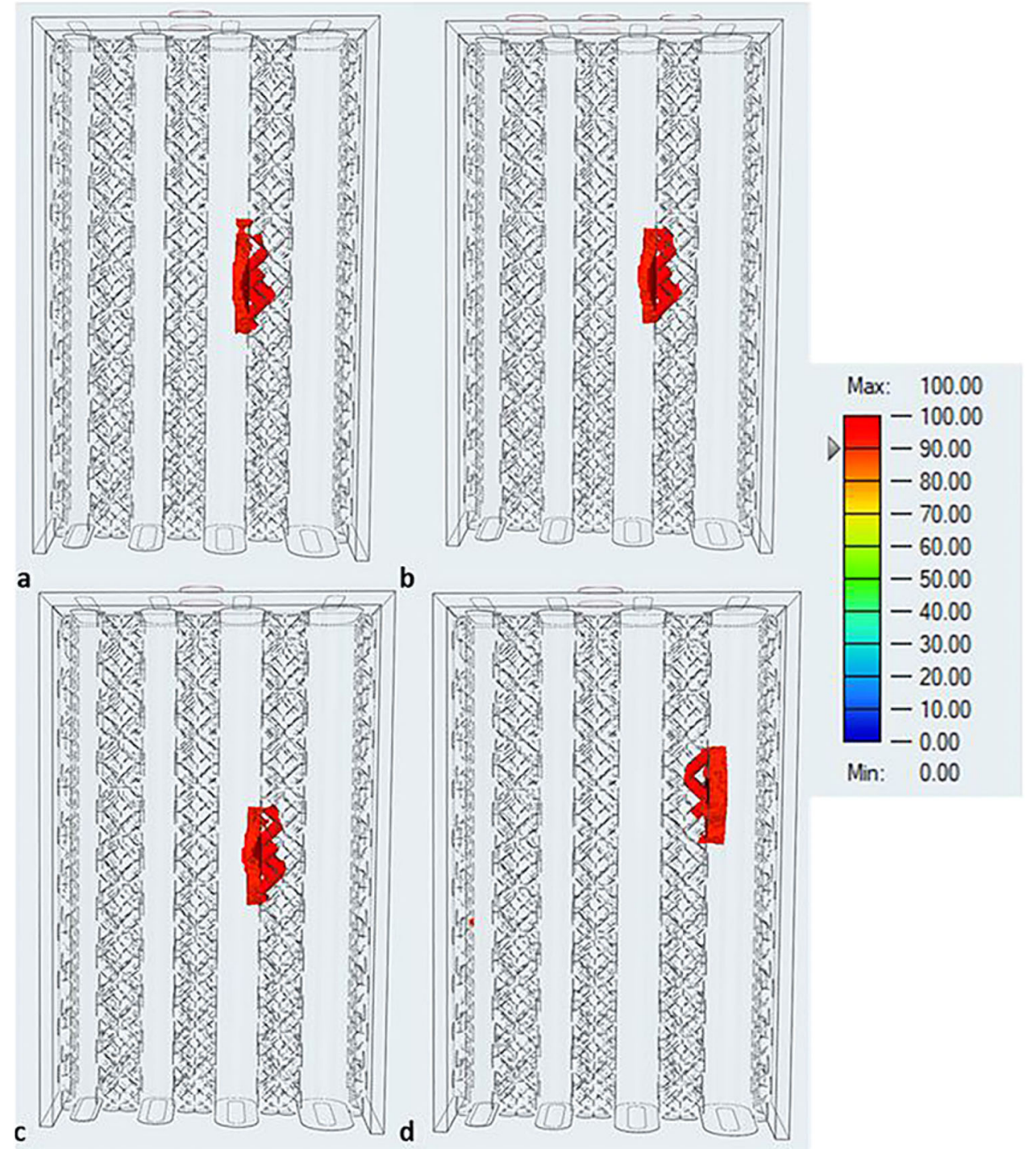

Figure 8. Porosity analysis for the $60 \mathrm{~mm}$ pipes model at the end of solidification for each gate configurations: (a) One inlet gate; (b) Three inlet gates; (c) Two inlet gates (lateral gate is near lowest thickness pipe); (d) Two inlet gates (lateral gate is near highest thickness pipe).

considered in the FEM simulations. This condition has determined the orientation of the components inside the cylinder in axis and not inclined. Indeed, the gates were assumed as perpendicular to the casting. The diameter of the gates was adopted constant in accordance with previous experiments. The diameter of gates was chosen to allow during the filling phase to avoid solidification. The cavity feeding process last $0.5 \mathrm{~s}$, according to experimental evidence that highlight how this value limits the formation of cold joints. Then, inlet gates with a radius of $1.6 \mathrm{~mm}$ were placed into the model considering different configuration, as shown in Figure 5. In particular, the different layouts analyzed have:

- One inlet gate placed on the upper face of the model;
- Three inlet gates placed on the upper face of the model;

- Two inlet gates placed, respectively, on the upper and lateral face of the model near the lowest thickness pipe;

- Two inlet gates placed, respectively, on the upper and lateral face of the model near the highest thickness pipe.

Sixteen scenarios were investigated for each pipe length and each inlet gate configuration. The best configuration was exploited for the actual casting process. 
Table 6. Simulation Time for the Various Gate Configurations and Pipe Length Analyzed

\begin{tabular}{|c|c|c|c|c|c|c|c|c|}
\hline \multirow{3}{*}{$\begin{array}{l}\text { Pipe length } \\
\text { Gate configuration }\end{array}$} & \multicolumn{8}{|c|}{ Solidification time [min] } \\
\hline & \multicolumn{2}{|l|}{$20 \mathrm{~mm}$} & \multicolumn{2}{|l|}{$40 \mathrm{~mm}$} & \multicolumn{2}{|l|}{$60 \mathrm{~mm}$} & \multicolumn{2}{|l|}{$80 \mathrm{~mm}$} \\
\hline & Start & End & Start & End & Start & End & Start & End \\
\hline 1 Upper Inlet & 273,59 & 296,84 & 284,33 & 317,12 & 334,81 & 376,20 & 380,39 & 429,04 \\
\hline 3 Upper Inlet & 274,94 & 298,04 & 285,33 & 317,61 & 335,19 & 376,92 & 380,23 & 429,68 \\
\hline 1 Upper 1 Lateral Inlet LH & 275,05 & 297,50 & 284,47 & 316,31 & 335,81 & 376,59 & 380,97 & 428,23 \\
\hline 1 Upper 1 Lateral Inlet RH & 274,53 & 298,06 & 284,32 & 317,19 & 334,81 & 376,42 & 380,04 & 429,61 \\
\hline
\end{tabular}

\section{Results}

Table 5 reports the simulation time for each gate configuration and pipe length. The scenario with the highest time provides for, on average, three inlet gates.

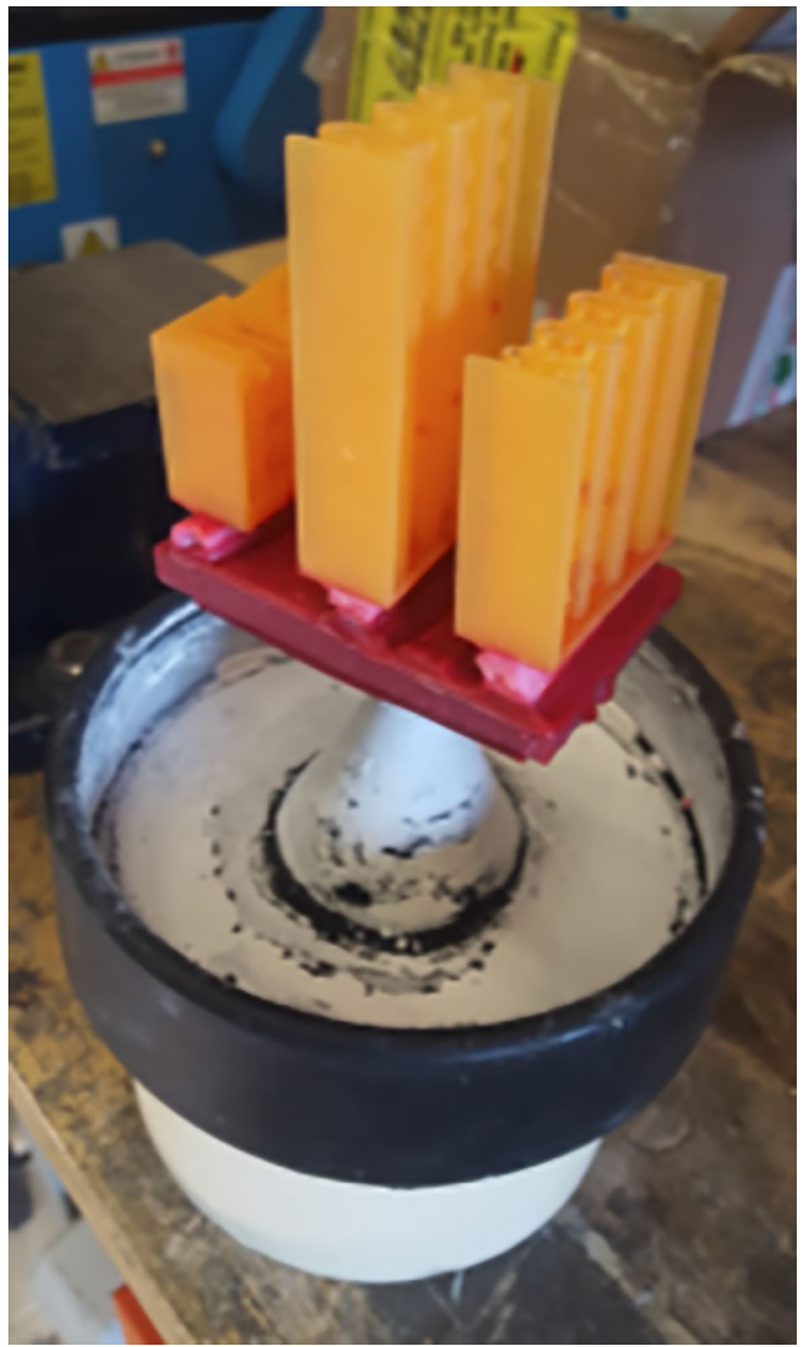

Figure 9. Resin models realized with the three upper inlet gate configuration chosen from the numerical simulations.
Therefore, an analysis was carried out to evaluate the trend of mould filling over time. The pipes length does not affect the mould filling; on the opposite, the inlet gate configuration has a significant impact. Figure 6 shows the molten metal state after $0.2 \mathrm{~s}$ for the $40 \mathrm{~mm}$ model. The cavity filling begins, for the configuration with a single inlet gate, in the central pipes $(1-1.5 \mathrm{~mm})$, where the metal reaches the bottom part of the mould. Indeed, these are the closest elements to the inlet gate. Three inlet gate led to a homogenous flow which distributes the metal evenly between the four pipes. This condition allows a reduction of the micro-porosities expected in the connection of the molten metal fronts. The configurations with the two gates have similar behavior concerning the central pipes. However, differences arise due to the different metal fronts produce by the cavity feeding. With the gate on the thinner

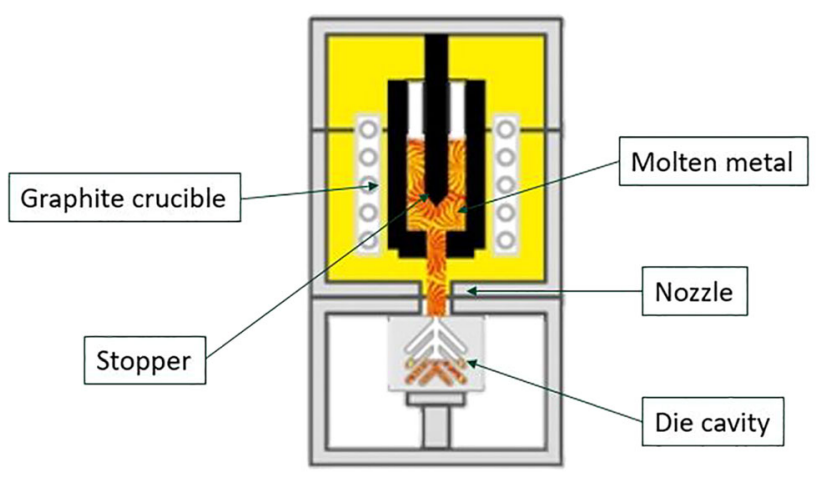

Figure 10. Scheme of casting furnace arrangement.

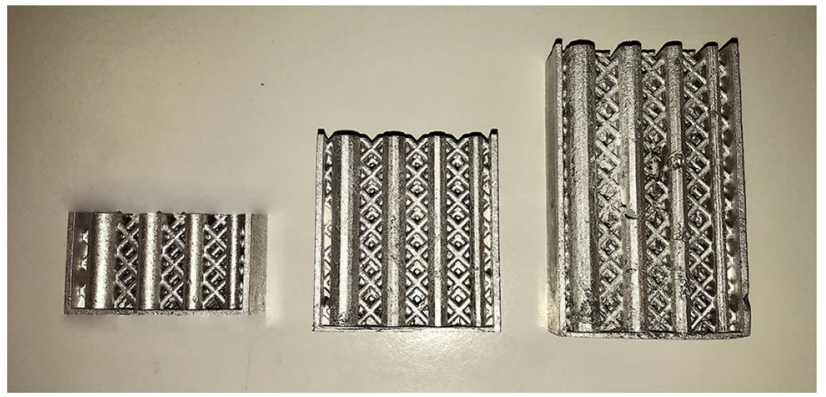

Figure 11. AC-44300 samples with the different pipe length obtained. 
tube, (c) configuration, the metal front connection occurs in the $1 \mathrm{~mm}$ pipe while in (d) in the $1.5 \mathrm{~mm}$ conduit. The molten metal fluxes conjunction area must be carefully considered, since affecting the casting process. High-velocity vectors may produce mold erosion and the embedding of plaster within the final structure. These latter considerations can be extended to the different pipe length. Figures 7 and 8 show, respectively, the micro-porosity and porosity analysis for the $60 \mathrm{~mm}$ pipes model at the end of solidification for each gate configuration. A single and the three inlet gate configurations allow achieving a casting without microporosity; on the other hand, two inlet gate produce micro porosities located in the pipes with a higher thickness (1.5 and $2 \mathrm{~mm})$. It is of particular relevance in the last configuration. Figure 8 shows the porosity distribution examined through the Niyama criterion. Except for the last scenario, (a) (b) and (c) configuration have a critical zone between $1.5 \mathrm{~mm}$ pipe and the reticular structure. In $(\mathrm{d})$, the porosity is focused between the $2 \mathrm{~mm}$ pipe and the reticular lattice, with a small point delocalized near the $0.5 \mathrm{~mm}$ tube.

Table 6 shows the solidification phase duration for the different gate configuration and pipes length. The filling period was imposed in the simulations to avoid cold joints during the filling process. Therefore, there are no notable differences in the solidification time between the various gate configurations evaluated.

In the light of the numerical analysis results, the configuration with three upper gates was selected for the actual casting process. The patterns were connected to the inlet gating system, and the casting realized with a foundry machine ASEG Galloni G5. The foundry process was realized in an Argon atmosphere while the metal injection in a vacuum condition. Following the casting process, the plaster was removed from the cylinder after 6 hours of cooling (Figure 9).

Figure 10 shows a scheme of casting furnace arrangement. Figure 11 shows the samples realized through the RIC process. The components realized are free from defect and macro-structural problems. The specimens exhibit accordance between the critical zones identified during numerical simulations, which validate the accuracy of the numerical model.

\section{Conclusions}

RIC is considered a very interesting process in the industrial field as it allows to have the advantages of the realization of complex shapes (typical of Additive Manufacturing processes) combined with lower realization costs related to foundry processes. During the design phase, it was possible to realize the interconnected thermal exchange structures (with thermal contact resistance for null hypotheses) with thermal vector elements (tubes).
During the printing phase, the limits have been the realization of models with $80 \mathrm{~mm}$ of pipes in how much the resin introduces a stiffness that on objects of this dimension it tends to deform and therefore to make to fail the process. The comparison between the results of the simulations and the samples carried out showed that the differences due to the melting process correspond, allowing the results obtained to be considered valid for the process design phase. Future developments related to this experimentation could be to develop a single module that constitutes a working model to evaluate the thermal performance of components made by RIC.

\section{Funding}

Open access funding provided by Università degli Studi di Roma Tor Vergata within the CRUI-CARE Agreement.

\section{Open Access}

This article is licensed under a Creative Commons Attribution 4.0 International License, which permits use, sharing, adaptation, distribution and reproduction in any medium or format, as long as you give appropriate credit to the original author(s) and the source, provide a link to the Creative Commons licence, and indicate if changes were made. The images or other third party material in this article are included in the article's Creative Commons licence, unless indicated otherwise in a credit line to the material. If material is not included in the article's Creative Commons licence and your intended use is not permitted by statutory regulation or exceeds the permitted use, you will need to obtain permission directly from the copyright holder. To view a copy of this licence, visit http://creativecommons.org/ licenses/by $/ 4.0 /$.

\section{REFERENCES}

1. S. Al-Bermani, M. Blackmore, W. Zhang, I. Todd, The origin of microstructural diversity, texture, and mechanical properties in electron beam melted ti-6al4v. Metall. Mater. Trans. 41(13), 3422-3434 (2010). https://doi.org/10.1007/s11661-010-0397-x

2. D. Almonti, G. Baiocco, E. Mingione, N. Ucciardello, Evaluation of the effects of the metal foams geometrical features on thermal and fluid-dynamical behavior in forced convection. Int. J. Adv. Manuf. Technol. 111(3), 1157-1172 (2020). https://doi.org/10.1007/ s00170-020-06092-1

3. D. Almonti, G. Baiocco, V. Tagliaferri, N. Ucciardello, Design and mechanical characterization of voronoi structures manufactured by indirect additive 
manufacturing. Mater. 13(5), 1085 (2020). https://doi. org/10.3390/ma13051085

4. D. Almonti, N. Ucciardello, Design and thermal comparison of random structures realized by indirect additive manufacturing. Mater. 12(14), 2261 (2019). https://doi.org/10.3390/ma12142261

5. T. Artaza, A. Alberdi, M. Murua, J. Gorrotxategi, J. Frías, G. Puertas, M. Melchor, D. Mugica, A. Suárez, Design and integration of waam technology and in situ monitoring system in a gantry machine. Proc. Manuf. 13, 778-785 (2017). https://doi.org/10.1016/j.promfg. 2017.09.184

6. M. Averyanova, P. Bertrand, B. Verquin, Studying the influence of initial powder characteristics on the properties of final parts manufactured by the selective laser melting technology: a detailed study on the influence of the initial properties of various martensitic stainless steel powders on the final microstructures and mechanical properties of parts manufactured using an optimized slm process is reported in this paper. Virtual and Phys. Prototyp. 6(4), 215-223 (2011). https://doi.org/10.1080/17452759.2011. 594645

7. G. Baiocco, V. Tagliaferri, N. Ucciardello, Neural networks implementation for analysis and control of heat exchange process in a metal foam prototypal device. Procedia CIRP 62, 518-522 (2017). https:// doi.org/10.1016/j.procir.2016.06.035

8. E. Brandl, U. Heckenberger, V. Holzinger, D. Buchbinder, Additive manufactured alsi10mg samples using selective laser melting (slm): Microstructure, high cycle fatigue, and fracture behavior. Mater. Des. 34, 159-169 (2012). https://doi.org/10.1016/j.matdes. 2011.07.067

9. D. Buchbinder, H. Schleifenbaum, S. Heidrich, W. Meiners, J. Bültmann, High power selective laser melting (hp slm) of aluminum parts. Phys. Procedia 12, 271-278 (2011). https://doi.org/10.1016/j.phpro. 2011.03.035

10. T. Caffrey, T. Wohlers, Manufacturing state of the Ind. Manuf. Eng. 154, 67-78 (2015)

11. P. Collins, D. Brice, P. Samimi, I. Ghamarian, H. Fraser, Microstructural control of additively manufactured metallic mater. Annu. Rev. Mater. Res. 46, 63-91 (2016). https://doi.org/10.1146/annurev-matsci070115-031816

12. C. Cunningham, S. Wikshåland, F. Xu, N. Kemakolam, A. Shokrani, V. Dhokia, S. Newman, Cost modelling and sensitivity analysis of wire and arc additive manufacturing. Proc. Manuf. 11, 650-657 (2017). https://doi.org/10.1016/j.promfg.2017.07.163

13. M.J. Davidson, K. Balasubramanian, G. Tagore, An experimental study on the quality of flow-formed aa6061 tubes. J. Mater. Process. Technol. 203(1-3), 321-325 (2008). https://doi.org/10.1016/j.jmatprotec. 2007.10.021
14. D. Ding, Z. Pan, D. Cuiuri, H. Li, Wire-feed additive manufacturing of metal components: technologies, developments and future interests. Int. J. Adv. Manuf. Technol. 81(1), 465-481 (2015). https://doi.org/10. 1007/s00170-015-7077-3

15. W. Everhart, S. Lekakh, V. Richards, J. Chen, K. Chandrashekhara, Crack formation during foam pattern firing in the investment casting process. Inter Metalcast 7(2), 7-14 (2013)

16. W. Everhart, S. Lekakh, V. Richards, J. Chen, H. Li, K. Chandrashekhara, Corner strength of investment casting shells. Inter Metalcast 7(1), 21-27 (2013). https://doi.org/10.1007/BF03355541

17. Y. Fang, J. Hu, J. Zhou, Y. Yu, Numerical simulation of filling and solidification in exhaust manifold investment casting. Int. J. Metalcast. 8(4), 39-45 (2014). https://doi.org/10.1007/BF03355593

18. W.E. Frazier, Metal additive manufacturing: a review. J. Mater. Eng. Perform. 23(6), 1917-1928 (2014). https://doi.org/10.1007/s11665-014-0958-Z

19. J. Ge, J. Lin, Y. Lei, H. Fu, Location-related thermal history, microstructure, and mechanical properties of arc additively manufactured $2 \mathrm{cr} 13$ steel using cold metal transfer welding. Mater. Sci. Eng.: A 715, 144-153 (2018). https://doi.org/10.1016/j.msea.2017. 12.076

20. N.P. Gokhale, P. Kala, V. Sharma, M. Palla, Effect of deposition orientations on dimensional and mechanical properties of the thin-walled structure fabricated by tungsten inert gas (tig) welding-based additive manufacturing process. J. Mech. Sci. Technol. 34(2), 701-709 (2020). https://doi.org/10.1007/s12206-0200115-6

21. B. Gorny, T. Niendorf, J. Lackmann, M. Thoene, T. Troester, H. Maier, In situ characterization of the deformation and failure behavior of non-stochastic porous structures processed by selective laser melting. Mater. Sci. Eng. A 528(27), $7962-7967$ (2011). https://doi.org/10.1016/j.msea.2011.07.026

22. S. Guarino, G. Di Ilio, S. Venettacci, Influence of thermal contact resistance of aluminum foams in forced convection: experimental analysis. Mater 10(8), 907 (2017). https://doi.org/10.3390/ ma10080907

23. H. Helmer, A. Bauereiß, R. Singer, C. Körner, Grain structure evolution in inconel 718 during selective electron beam melting. Mater. Sci. Eng. A 668, 180-187 (2016). https://doi.org/10.1016/j.msea.2016. 05.046

24. D. Herzog, V. Seyda, E. Wycisk, C. Emmelmann, Additive manufacturing of metals. Acta Mater. 117, 371-392 (2016). https://doi.org/10.1016/j.actamat. 2016.07.019

25. Z. Hu, X. Qin, T. Shao, Welding thermal simulation and metallurgical characteristics analysis in waam for 5 crnimo hot forging die remanufacturing. Procedia 
Eng. 207, 2203-2208 (2017). https://doi.org/10.1016/ j.proeng.2017.10.982

26. P.H. Huang, C.J. Lin, Computer-aided modeling and experimental verification of optimal gating system design for investment casting of precision rotor. Int. J. Adv. Manuf. Technol. 79(5), 997-1006 (2015). https://doi.org/10.1007/s00170-015-6897-5

27. Y. Kok, X.P. Tan, P. Wang, M. Nai, N.H. Loh, E. Liu, S.B. Tor, Anisotropy and heterogeneity of microstructure and mechanical properties in metal additive manufacturing: A critical review. Mater. \& Des. 139, 565-586 (2018). https://doi.org/10.1016/j. matdes.2017.11.021

28. S.. Leuders, M.. Thöne, A. Riemer, T. Niendorf, T. Tröster, H.A. Richard, H. Maier, Fatigue resistance and crack growth performance, On the mechanical behaviour of titanium alloy tial6v4 manufactured by selective laser melting. Int. J. Fatigue 48, 300-307 (2013). https://doi.org/10.1016/j.ijfatigue.2012.11.011

29. Y. Luo, J. Li, J. Xu, L. Zhu, J. Han, C. Zhang, Influence of pulsed arc on the metal droplet deposited by projected transfer mode in wire-arc additive manufacturing. J. Mater. Process. Technol. 259, 353-360 (2018). https://doi.org/10.1016/j.jmatprotec. 2018.04.047

30. M. Ma, Z. Wang, X. Zeng, A comparison on metallurgical behaviors of 3161 stainless steel by selective laser melting and laser cladding deposition. Mater. Sci. Eng. A 685, 265-273 (2017). https://doi. org/10.1016/j.msea.2016.12.112

31. L. Murr, S. Quinones, S. Gaytan, M. Lopez, A. Rodela, E. Martinez, D. Hernandez, E. Martinez, F. Medina, R. Wicker, Microstructure and mechanical behavior of ti-6al-4v produced by rapid-layer manufacturing, for biomedical applications. J. Mech. Behav. Biomed. Mater. 2(1), 20-32 (2009). https:// doi.org/10.1016/j.jmbbm.2008.05.004

32. M. Odabaee, S. Mancin, K. Hooman, Metal foam heat exchangers for thermal management of fuel cell systems-an experimental study. Exp. Therm. Fluid Sci. 51, 214-219 (2013). https://doi.org/10.1016/j. expthermflusci.2013.07.016

33. J. Ouyang, H. Wang, R. Kovacevic, Rapid prototyping of 5356-aluminum alloy based on variable polarity gas tungsten arc welding: process control and microstructure. Mater. Manuf. Process. 17(1), 103-124 (2002). https://doi.org/10.1081/AMP120002801

34. A.J. Pinkerton, Advances in the modeling of laser direct metal deposition. J. Laser Appl. 27(S1), S15001 (2015). https://doi.org/10.2351/1.4815992

35. B. Podder, C. Mondal, K.R. Kumar, D. Yadav, Effect of preform heat treatment on the flow formability and mechanical properties of aisi4340 steel. Mater. Des. 37, 174-181 (2012). https://doi.org/10.1016/j.matdes. 2012.01.002
36. J.L. Prado-Cerqueira, A.M. Camacho, J.L. Diéguez, Á. Rodríguez-Prieto, A.M. Aragón, C. LorenzoMartín, Á. Yanguas-Gil, Analysis of favorable process conditions for the manufacturing of thin-wall pieces of mild steel obtained by wire and arc additive manufacturing (waam). Mater 11(8), 1449 (2018). https:// doi.org/10.3390/ma11081449

37. K. Rajan, P. Deshpande, K. Narasimhan, Effect of heat treatment of preform on the mechanical properties of flow formed aisi 4130 steel tubes-a theoretical and experimental assessment. J. Mater. Process. Technol. 125, 503-511 (2002). https://doi.org/10. 1016/S0924-0136(02)00305-9

38. R. Rybár, M. Beer, D. Kudelas, B. Pandula, Copper metal foam as an essential construction element of innovative heat exchanger. Metalurgija 55(3), 489-492 (2016)

39. W.J. Sames, F. List, S. Pannala, R.R. Dehoff, S.S. Babu, The metallurgy and processing science of metal additive manufacturing. Int. Mater. Rev. 61(5), 315-360 (2016). https://doi.org/10.1080/09506608. 2015.1116649

40. N. Shamsaei, A. Yadollahi, L. Bian, S.M. Thompson, An overview of direct laser deposition for additive manufacturing; part ii: mechanical behavior, process parameter optimization and control. Addit. Manuf. 8, 12-35 (2015). https://doi.org/10.1016/j.addma.2015. 07.002

41. X. Shi, S. Ma, C. Liu, Q. Wu, J. Lu, Y. Liu, W. Shi, Selective laser melting-wire arc additive manufacturing hybrid fabrication of ti-6al-4v alloy: microstructure and mechanical properties. Mater. Sci. Eng. A 684, 196-204 (2017). https://doi.org/10.1016/j.msea. 2016.12.065

42. A. Shirizly, O. Dolev, From wire to seamless flowformed tube: leveraging the combination of wire arc additive manufacturing and metal forming. Jom 71(2), 709-717 (2019). https://doi.org/10.1007/s11837-0183200-x

43. M. Simonelli, Y.Y. Tse, C. Tuck, Effect of the build orientation on the mechanical properties and fracture modes of slm ti-6al-4v. Mater. Sci. Eng. A 616, 1-11 (2014). https://doi.org/10.1016/j.msea.2014.07.086

44. S. Singamneni, O. Diegel, D. Singh, N. McKenna, Rapid casting of light metals: An experimental investigation using taguchi methods. Inter Metalcast 5(3), 25-36 (2011). https://doi.org/10.1007/ BF03355516

45. S. Singh, S. Ramakrishna, R. Singh, Material issues in additive manufacturing: a review. J. Manuf. Process. 25, 185-200 (2017). https://doi.org/10.1016/j.jmapro. 2016.11.006

46. J. Smith, W. Xiong, W. Yan, S. Lin, P. Cheng, O.L. Kafka, G.J. Wagner, J. Cao, W.K. Liu, Linking process, structure, property, and performance for metal-based additive manufacturing: computational approaches with experimental support. Comput. 
Mech. 57(4), 583-610 (2016). https://doi.org/10.1007/ s00466-015-1240-4

47. A.B. Spierings, G. Levy, Comparison of density of stainless steel 3161 parts produced with selective laser melting using different powder grades. In: Proceedings of the Annual International Solid Freeform Fabrication Symposium, pp. 342-353. Austin, TX (2009)

48. G. Strano, L. Hao, R.M. Everson, K.E. Evans, Surface roughness analysis, modelling and prediction in selective laser melting. J. Mater. Process. Technol. 213(4), 589-597 (2013). https://doi.org/10.1016/j. jmatprotec.2012.11.011

49. S.M. Thompson, Z.S. Aspin, N. Shamsaei, A. Elwany, L. Bian, Additive manufacturing of heat exchangers: a case study on a multi-layered ti-6al-4v oscillating heat pipe. Addit. Manuf. 8, 163-174 (2015). https://doi. org/10.1016/j.addma.2015.09.003

50. S.M. Thompson, L. Bian, N. Shamsaei, A. Yadollahi, An overview of direct laser deposition for additive manufacturing; part i: transport phenomena, modeling and diagnostics. Addit. Manuf. 8, 36-62 (2015). https://doi.org/10.1016/j.addma.2015.07.001

51. D. Wang, B. He, S. Liu, C. Liu, L. Fei, Dimensional shrinkage prediction based on displacement field in investment casting. Int. J. Adv. Manuf. Technol 85(1), 201-208 (2016). https://doi.org/10.1007/s00170-0157836-1

52. H. Wang, W. Jiang, J. Ouyang, R. Kovacevic, Rapid prototyp. of 4043 al-alloy parts by vp-gtaw. J. Mater. Process. Technol. 148(1), 93-102 (2004). https://doi. org/10.1016/j.jmatprotec.2004.01.058

53. J. Wang, S.R. Sama, P.C. Lynch, G. Manogharan, Design and topology optimization of 3d-printed wax patterns for rapid investment casting. Procedia Manuf. 34, 683-694 (2019). https://doi.org/10.1016/j.promfg. 2019.06.224

54. B. Wu, Z. Pan, S. Li, D. Cuiuri, D. Ding, H. Li, The anisotropic corrosion behaviour of wire arc additive manufactured ti-6al-4v alloy in 3.5\% nacl solution. Corr. Sci. 137, 176-183 (2018). https://doi.org/10. 1016/j.corsci.2018.03.047

55. X. Wu, J. Liang, J. Mei, C. Mitchell, P. Goodwin, W. Voice, Microstructures of laser-deposited ti-6al-4v. Mater. \& Des. 25(2), 137-144 (2004). https://doi.org/ 10.1016/j.matdes.2003.09.009
56. W. Xiong, G.B. Olson, Integrated computational mater. design for high-performance alloys. MRS Bull. 40(12), 1035-1044 (2015). https://doi.org/10.1557/ mrs. 2015.273

57. W. Xiong, G.B. Olson, Cybermaterials: materials by design and accelerated insertion of materials. NPJ Comput. Mater. 2(1), 1-14 (2016). https://doi.org/10. 1038/npjcompumats.2015.9

58. X. Xu, S. Ganguly, J. Ding, S. Guo, S. Williams, F. Martina, Microstructural evolution and mechanical properties of maraging steel produced by wire + arc additive manufacture process. Mater. Charact. 143, 152-162 (2018). https://doi.org/10.1016/j.matchar. 2017.12.002

59. F. Yan, W. Xiong, E.J. Faierson, Grain structure control of additively manufactured metallic mater. Mater 10(11), 1260 (2017). https://doi.org/10.3390/ ma10111260

60. L. Yang, H. Gong, S. Dilip, B. Stucker, An investigation of thin feature generation in direct metal laser sintering systems. In: Proc. 26th Annu. Int. Solid Free. Fabr. Symp, pp. 714-731 (2014)

61. T. Zhang, X.F. Liu, S.S. Kong, J.J. Fan, Z.D. Zhang, Preparation and fundamental research of continuous through-porous pure aluminum flat pipes by depoling continuous casting. In: Mater. Sci. Forum, vol. 898, pp. 1220-1230. Trans Tech Publ (2017). https://doi. org/10.4028/www.scientific.net/MSF.898.1220

62. H. Zhao, P.K.S. Nam, V.L. Richards, S.N. Lekakh, Thermal decomposition studies of eps foam, polyurethane foam, and epoxy resin (sla) as patterns for investment casting; analysis of hydrogen cyanide (hen) from thermal degradation of polyurethane foam. Inter Metalcast. 13(1), 18-25 (2019). https://doi.org/ 10.1007/s40962-018-0240-5

63. Y. Zhu, D. Liu, X. Tian, H. Tang, H. Wang, Characterization of microstructure and mechanical properties of laser melting deposited ti-6.5 al-3.5 mo$1.5 \mathrm{zr}-0.3$ si titanium alloy. Mater. Des. 56, 445-453 (2014). https://doi.org/10.1016/j.matdes.2013.11.044

Publisher's Note Springer Nature remains neutral with regard to jurisdictional claims in published maps and institutional affiliations. 